not to place the LVAD using bivalirudin or any other direct thrombin inhibitors because this is associated with potentially lethal bleeding complications. ${ }^{3}$ Some centers have reported the use of unfractionated heparin and concomitant potent platelet inhibitors for CPB in the setting of HIT. However, this approach has not been adopted at our institution.

The use of plasmapheresis for HIT is not a novel conception. Few studies have reported using plasma exchange in the management of HIT with thrombosis. ${ }^{4}$ However, the surgical literature contains only 1 case report in which plasmapheresis was successfully used preoperatively in a HIT-positive patient who required coronary artery bypass grafting under $\mathrm{CPB}$ with heparin. ${ }^{5}$ To our knowledge, this is the first reported case of plasmapheresis for a HIT-positive patient requiring an LVAD.

This isolated experience suggests that plasmapheresis may be used successfully to seroconvert a patient to
HIT-negative status. This allows for the patient to safely undergo cardiac surgery with CPB using systemic heparinization. The more widespread use of this strategy should be corroborated in a larger patient population.

\section{References}

1. Warkentin TE, Greinacher A. Heparin-induced thrombocytopenia and cardiac surgery. Ann Thorac Surg. 2003;76:638-48.

2. Riess FC. Anticoagulation management and cardiac surgery in patients with heparininduced thrombocytopenia. Semin Thorac Cardiovasc Surg. 2005;17:85-96.

3. Christiansen S, Jahn UR, Meyer J, Scheld HH, Van Aken H, Kehrel BE, et al. Anticoagulative management of patients requiring left ventricular assist device implantation and suffering from heparin-induced thrombocytopenia. Ann Thorac Surg. 2000;69:774-7.

4. Bouvier JL, Lefevre P, Villain P, Elias A, Durand JM, Juhan I, et al. Treatment of serious heparin-induced thrombocytopenia by plasma exchange: report on four cases. Thromb Res. 1988;51:335-6.

5. Kajitani M, Aguinaga M, Johnson CE, Scott MA, Antakli T. Use of plasma exchange and heparin during cardiopulmonary bypass for a patient with heparin induced thrombocytopenia: a case report. J Card Surg. 2001;16:313-8.

\title{
Hemophagocytic syndrome: A rare but specific complication of lung transplantation
}

\author{
Takahiro Oto, ${ }^{\mathrm{a}}$ Gregory I. Snell, ${ }^{\mathrm{b}}$ Keiji Goto, ${ }^{\mathrm{c}}$ and Shinichiro Miyoshi, ${ }^{\mathrm{a}}$ Okayama, Japan, and Melbourne, \\ Australia
}

Hemophagocytic syndrome (HPS) is a rare but occasionally life-threatening complication after solid organ transplantation. ${ }^{1,2}$ This syndrome is characterized by phagocytizing histiocytes that infiltrate tissues and phagocytize blood elements and their precursors. The cause of this syndrome is unknown. ${ }^{3}$ The development of HPS has been associated with an uncontrolled excessive inflammatory response, and the timely initiation of potentially life-saving therapy with immunoglobulins and steroids is mandatory. Nonetheless, the reported prognosis of this syndrome remains poor. ${ }^{1-3}$ There is no published information regarding HPS in lung transplantation.

\footnotetext{
From the Department of Thoracic Surgery, ${ }^{\text {a }}$ Okayama University Hospital, Okayama Japan; the Department of Allergy, Immunology and Respiratory Medicine, ${ }^{\mathrm{b}}$ The Alfred Hospital, Melbourne, Australia; and the Department of Anesthesiology and Resuscitology, ${ }^{\mathrm{c}}$ Okayama University Hospital, Okayama, Japan.

Disclosures: None.

Received for publication March 3, 2010; revisions received April 30, 2010; accepted for publication May 16, 2010; available ahead of print June 16, 2010.

Address for reprints: Takahiro Oto, MD, Department of Thoracic Surgery, Okayama University Hospital, 2-5-1, Shikata-cho, Okayama, 700-8558, Japan (E-mail: oto@ md.okayama-u.ac.jp).

J Thorac Cardiovasc Surg 2010;140:e58-9

$0022-5223 / \$ 36.00$

Copyright (c) 2010 by The American Association for Thoracic Surgery

doi:10.1016/j.jtcvs.2010.05.021
}

We report a case of severe HPS related to Pseudomonas infection in a lung transplant recipient.

\section{CLINICAL SUMMARY}

A living-donor single lobar lung transplant was performed for a patient with pulmonary veno-occlusive disease. The primary immunosuppression consisted of 2 single doses of basiliximab, daily doses of methylprednisolone, followed by maintenance immunosuppression with tacrolimus (target trough level: 10-15 ng/mL), mycophenolate mofetil, and prednisolone. Results of blood tests for hepatitis $\mathrm{C}$ virus, hepatitis B virus, cytomegalovirus, and Epstein-Barr virus of the donor and the recipient were negative.

Pancytopenia (hemoglobin $8.3 \mathrm{~g} / \mathrm{dL}$, platelets $5 \times 104 / \mu \mathrm{L}$, and neutrophils $0.6 \times 103 / \mu \mathrm{L}$ ) was first noted as a clinical problem 8 weeks after transplant (Figure 1). Low-grade fever and mild splenomegaly were present. Elevated levels of interleukin-2 receptor $(2355 \mathrm{U} / \mathrm{mL}$ [normal range $<650])$, ferritin $(6338 \mathrm{ng} / \mathrm{mL}[<138])$, triglycerides $(193 \mathrm{mg} / \mathrm{dL}$ $[<150])$, aspartate aminotransferase (48 IU/L $[<35])$, alanine aminotransferase (73 IU/L $[<42]$ ), alkaline phosphatase $(630 \mathrm{IU} / \mathrm{L}[<360]), \gamma$-glutanyl transferase $(182 \mathrm{IU} / \mathrm{L}$ $[<40])$, and fibrinogen $(420 \mathrm{mg} / \mathrm{dL}[<390])$ were also noted. Bone marrow aspiration revealed massive hemophagocytic 


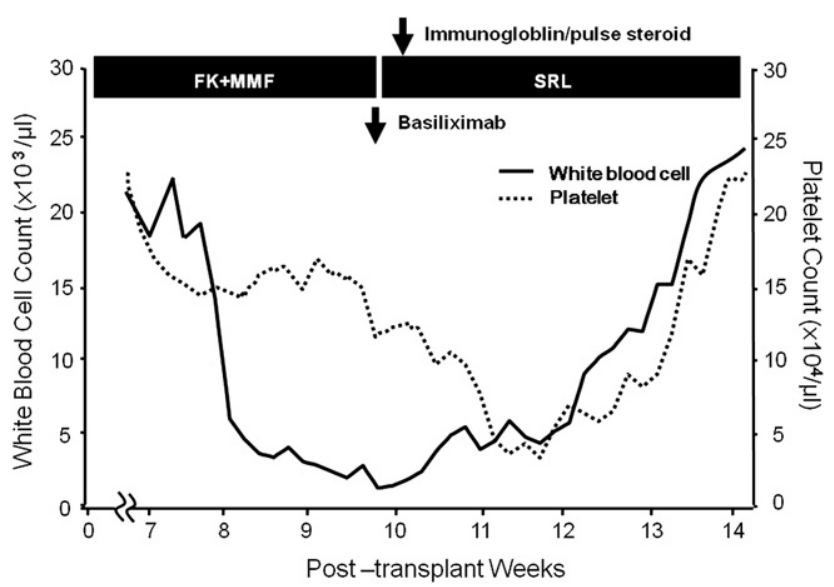

FIGURE 1. Leukopenia and thrombocytopenia markedly improved after initiation of sirolimus ( $S R L)$, basiliximab, immunoglobulin, and pulsedsteroid therapy. $F K$, Tacrolimus; $M M F$, mycophenolate mofetil.

reaction (Figure 2). Sources of infection were sought to explain this possible HPS. Pseudomonas producing metallo- $\beta$-lactamase, previously detected as an asymptomatic presumed colonizing organism in the native lung, was now noted to be causing a new problem of bronchitis/mild pneumonitis with a simultaneous and persistent increasing elevation of the white blood cell count (from 15 to $23 \times 103 / \mu \mathrm{L}$ ). After discontinuation of calcineurin inhibitor and after initiation of sirolimus, basiliximab, immunoglobulin, and steroid pulse therapy, leukopenia/thrombocytopenia markedly improved, with the patient recovering from the HPS. After a short period of stability, Pseudonomas pneumonia worsened. Despite aggressive antibiotic therapy, including imipenem/cilastatin, aztreonam, tazobactam/piperacillin, and polymyxin as a last resort, 4 weeks later this now multidrug-resistant Pseudomonas aeruginosa caused a fatal bacterial septicemia.

\section{DISCUSSION}

HPS is a rare but significant complication after solid organ transplantation. To our knowledge, this is the first report of HPS in lung transplantation.

HPS is a sepsis-associated condition characterized by a highly stimulated but miss-directed immune response. This syndrome is often caused by exogenous agents (infectious organisms, toxins) and endogenous products (tissue damage, metabolic products), and it is associated with pancytopenia, coagulopathy, and liver dysfunction. ${ }^{3}$ When a patient has fever, pancytopenia, and splenomegaly, HPS should be considered. ${ }^{3}$ The clinical and laboratory diagnostic criteria are as follows: (1) fever, (2) splenomegaly, (3) cytopenia of 2 cell lines or more (hemoglobin, platelets, and

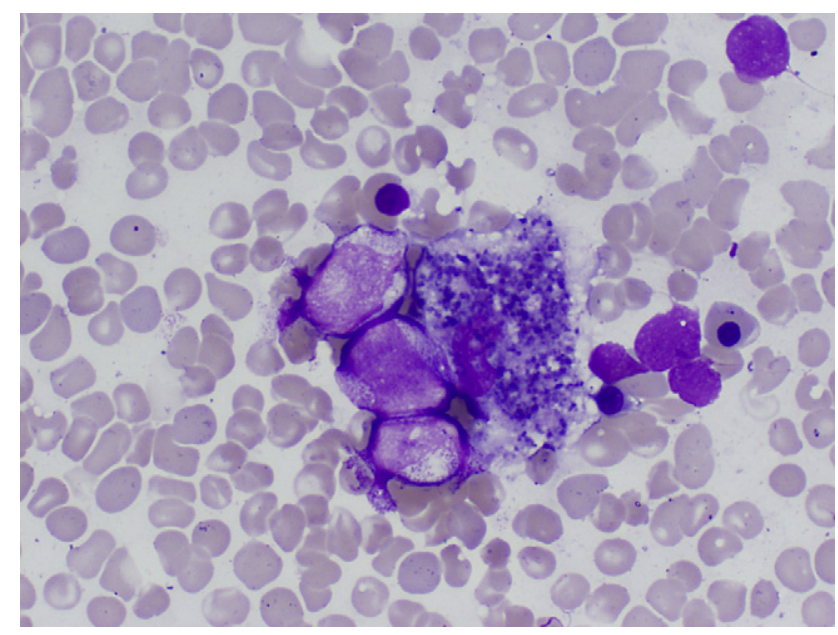

FIGURE 2. Light microscopic image of bone marrow aspiration showing macrophages containing blood cells in their cytoplasm.

neutrophils), (4) hypertriglyceridemia and/or hypofibrinogenemia, (5) elevated ferritin, (6) elevated interleukin-2 receptor, (7) decreased natural killer cell activity, and (8) hemophagocytosis in bone marrow $\left(>5 / 8\right.$ criteria). ${ }^{3}$ Immunocompromised patients are thought to be more prone to the development of HPS, probably because it is triggered by opportunistic infections. According to the largest case series of kidney transplant recipients, the incidence of HPS was $0.4 \%$ with a mortality of $47 \%{ }^{1}$ In the current case, no viral or new bacterial infections were detected after transplant; however, the persistence of multidrug-resistant $\mathrm{Pseu}$ domonas in the recipient airways may well have provided the initial infectious stimulus. In general, in HPS hyperinflammation can be treated with steroid therapy and calcineurin inhibitor blocking the T-lymphocyte response. Reduction of immunosuppression and immunoglobulin infusion helping to control the infection and will block B-lymphocyte responses. ${ }^{1,2}$ In the current case, sirolimus, basiliximab, immunoglobulin, and steroid pulse therapy were successfully used to downregulate the response of both $\mathrm{B}$ and $\mathrm{T}$ cells to the overproduction of interleukin 2 .

In conclusion, HPS is a significant diagnostic and therapeutic challenge in lung transplantation. Awareness of the diagnostic criteria of this rare, but potentially fatal, complication is important if timely therapies are to be initiated.

\section{References}

1. Karras A, Thervet E, Legendre C. Groupe Coopératif de transplantation d'Ile de France. Hemophagocytic syndrome in renal transplant recipients: report of 17 cases and review of literature. Transplantation. 2004;77:238-43.

2. Asci G, Toz H, Ozkahya M, Cagirgan S, Duman S, Sezis S, et al. High-dose immunoglobulin therapy in renal transplant recipients with hemophagocytic histiocytic syndrome. J Nephrol. 2006;19:322-6.

3. Janka GE. Hemophagocytic syndromes. Blood Rev. 2007;21:245-53. 